Agnieszka Oberc*

University of Wroclaw

\title{
I WRITE. YOU WRITE. THEY WRITE. THE LITERARY WORKS OF FANDOM AS A FACTOR IN INTEGRATING THE COMMUNITY
}

\begin{abstract}
Fanfiction is a fiction based on situations and characters that have been created by someone else. It is written by fans who use original texts to create their own art and culture.Writing fanfiction is something that fans do together. They discuss original texts, share their views and opinions about plot and characters, and create common interpretation that can be used by other fandom members. They also participate in creating new texts by commenting on fanficks published by other fans. Writing is not only a way to express fans opinions about their favourite books and shows, but also an opportunity to spend time with people sharing their interests. Analysis of fan-created texts shows not only its importance to individual fans, but also a vital role writing fanfiction plays in building fan communities and creating bonds between their members.
\end{abstract}

Key words: fanfiction, fan communities, fandom, writing and reading

Fanfiction is defined as stories set in worlds or using characters created by other authors. The fans write to fill the gaps in original texts, continue familiar stories, or create alternative universes. Most fanfiction is written within fandom, that is, communities of fans gathering around given works of fiction. Fandom is a subculture whose existence is based on other people's creations; the members take their creations, and use them to create their own artifacts, as well as build group traditions. The fans rewrite source texts to adapt them to their own needs; they actively participate

* Insitute of Polish Philology, University of Wrocław, Plac Nankiera 15, 50-140 Wrocław, e-mail: agnieszka.oberc@gmail.com 
in culture, and create their own art. Fandom creativity can take different shapes and forms. Apart from works of fiction, one can find examples of visual arts ("fanart"), music ("filk"), and audiovisual arts ("fanvid"). Regardless of form, all fandom's creations are based on the source text, which is usually refered to as "canon". Canon is what binds fans as a group, giving them creative space within which they can act. In a way, canon is the source of group identity, since most fans identify with the groups within which they create. Saying: "I'm a Star Trek fan" means declaring oneself as a member of a group that has its unique traditions, different, for example, of those cultivated by Harry Potter fans - although, of course, there are many elements that both groups share.

While some people are satisfied with belonging to just one fandom, others eventually start discovering other texts as well. Through broadening the scope of canon texts, a fan becomes a member of a community described by Henry Jenkins as media fandom (Jenkins 1992: 1). What is specific to this group is focusing not on one text, but on multiple texts at once: movies, TV shows, anime, comics, computer games, and popular literature.

It is generally understood that one becomes a fan of a text due to genuine fascination. After familiarizing oneself with a text and becoming drawn to it, a potential fandom member starts seeking contacts with other enthusiasts, gradually becoming more and more involved in fan culture. In media fandom, however, another phenomenon is observed: wanting to become a part of a specific fandom is a key factor in choosing texts to read. For example, fans can start watching a TV show not because they particularly enjoy the premise, but because there is a lot of good fanfiction in the show's fandom, or because an author they enjoy writes in more than one fandom.

Fanfiction is always a re-creation depending on the source text on which it is based. On one hand, this allows the fanfic writer to ommit certain elements of world-building, because their readers, familiar with the canon, understand hints just as well as direct statements. On the other hand, the reader can only fully comprehend a piece of fanfiction if they are familiar with the source text. Some works of fanfiction require in-depth knowledge of the canon, for others it is enough to be familiar with a few basic facts, but in any case, consuming fanfiction always needs to be related to the source text. In result, a fan can have a few favorite source texts which they can analyze, and they can have a few otherswhich they only know well enough to read fanfiction and participate in discussions. Due to the sheer size of fandom it is difficult to cite exact numbers, but from observing users' profiles on fanfiction.net one can conclude that there is a tendency to read fanfiction in multiple fandoms, while only creating in a few of them. 
In this context, one should pay particular attention to the role of writing fanfiction in identifying with fandom. According to Sheenagh Pugh, fandom as a whole is a federation of independent republics rather than a kingdom (Pugh 2005: 116). Every single fandom can have its own area of interest, and in some cases, a particular fandom might have little in common with the other, but the activity of fanfiction writing goes beyond fandom borders. Writing might be only one of many examples of fandom activity, but for groups writing and commenting on fanfiction, the creative process is very closely linked to binding the group together, which, especially in media fandom, helps to create a common culture based on many texts.

\section{Fanfiction as interpretation}

When considering fanfiction, one should first and foremost look at the reception of source text, because in the case of fanfiction, reception and creation seem to be inseparable processes. Canon text is not only an inspiration, but also a material from which a new work is fashioned. Most fans consume source texts alone, reading or watching in their homes (however, there are examples of groups gathering to watch movies or TV shows together). What separates a fan from a casual viewer is that, after consuming a text, they enter a discussion with other fans. Jenkins describes reading as a "social process through which individual interpretations are shaped and reinforced through ongoing discussions with other readers" (Jenkins 1992: 44).

One could say that discussion is the very basis of fandom. During conversations held on internet forums, as well as reading and commenting on other fans' stories fandom engages in a continuous debate about the source text. One of the aims of this discussion is the exchange of information. On many discussion forums there are special threads in which fans can find information about characters or worlds. A good example can be The Harry Potter Zone (Strefa Harry'ego Pottera) on Mirriel forum, where various pieces of information (including facts from minor characters' lives, characters' birthdays, wand cores etc) can be found.

However, the main aim of fans' interactions is to interpret the canon. Jenkins describes fandom as a critical environment, classifying fanfiction as a form of a critical text (Jenkins 1992: 88), while Kristina Busse and Karen Hellekson in Work in Progress notices similarities between fandom and academia. Those statements seems to be confirmed by the way fans 
approach the canon: they analyze it with care and great attention to detail, and their works tend to absorb multiple theories; complimentary as well as mutually exclusive ones. On the other hand, fannish interpretation is often very different from one that could be expected in academic discourse. Fandom analysis goes beyond the source text, allowing the fans to add events that do not take place in the canon. They do not just analyze what happened; they are also interested in what could have happened, and what, according to them, should have happened. Very often they emphasize elements that are marginal in the source text (minor characters, undeveloped plots). The main difference between fandom and academia is the intimate relationship between the fan and the text, which breaches the distance between a work of art and its recipient. The line between the fictional and the personal is blurry, because the metatext created around the source text can be based on personal experience, which broadens the scope of analysis. Fandom discussions can be focused on the personal (for example using the fan's failed relationships to explain what is happening between characters), which means that fictional events can be helpful to interpret what is happening in one's personal life.

The aforementioned lack of distance is one of the reasons why fans are often accused of not being able to tell the difference between fiction and reality. However, it is worth remembering that distance or lack of thereof are merely strategies a reader can choose while approaching the text. Neither is inherently superior to the other, and the recipient is allowed to change their approach according to their needs. Most fans are capable of consuming their favorite texts both with distance and with great emotional investment. On one hand, they are interested in how a particular text came to be: they read interviews with writers, producers or actors, they familiarize themselves with filming techniques, special effects, or changes in scripts. They take a text apart to see how an illusion is created. On the other hand, they allow themselves to be invested in personal worlds, treating the characters like real people whose stories and emotions can be analyzed. "Fans see the fictional characters and their actions as simultaneously "real" and "constructed", adopting a strategy of "double viewing" that treats the show with both suspended disbelief and ironic distance." (Jenkins 1992: 67).

Another aim of fandom discussions is exchange of personal information between participants. It is common to combine a personal chat with a discussion of the canon, which allows analysis to be conducted as well as building relationships at the same time. Thanks to the internet, the fans are no longer limited to local communities, but they can meet people from 
all around the world. Face-to-face encounters remain important in fandom life, but in case of people living on different continents, they are not always possible. Exchanging personal information during fandom discussion is, therefore, even more important, because it allows the fans to get to know each other.

Due to interactions between fandom members, individual opinions start to melt into common interpretations. This is how fanon, defined as a collection of all fanmade elements, is created. Fanon includes interpretations as well as elements of the canon world. Fans discuss the source text, read each other's stories, comment, and sometimes even include other fan's ideas in their own fanfiction. Some ideas are elaborated on, others are not met with much interest. As a result, established ways of perceiving events and characters are created. Of course the size of fandom prevents it from proposing readings every single member would subscribe to; instead, it creates a set of common interpretations.

A good example of this phenomenon is fandom's ways of describing Ronald Weasley in fanfiction based on the Harry Potter universum. Ron is often presented as Harry's best friend who accompanies him in his adventures, but it is equally common to focus on his traits that suggest that he is merely an immature brat who is jealous of his friend's fame. This leads to two basic versions of Ron (positive and negative) being created. It seems particularly interesting that those two interpretations, despite being schematic, are immensely popular, which shows how subjective fannish interpretation can be. Both views are firmly based on canon events, but they emphasize them differently, thus creating two completely different characters. Most fanfiction including Ron subscribes to one version or the other.

Those basic interpretations are then used by fans, who develop them by adding more elements. Due to interpretations being very schematic one could conclude that any resemblence between particular depictions are purely coincidental. However, I would argue that established "versions" of characters do, indeed, exist, because every such reading is accompanied by a set of typical "additional features". For example, a meek, reasonable Remus Lupin is often a chocolate addict, while Remus the Werewolf's eyes turn amber when he is angry. None of those elements is relevant to the plot, but they appear often enough to attract the reasercher's attention.

Fans use not only those pieces of information regarded as common property (i.e. interpretations, or such elements of canon texts that have lost its connection to the author). They also utilize other fans' creations in their 
artistic expression. A writer can introduce an original character created by another writer, or set their story in an alternative universe produced by other fans. Every fan-created text belongs to a complicated net of texts which are its source as well as its context.

\section{Fanfiction as literature}

A story idea is usually discussed between friends, and as a result, it often happens that two writers decide to write together, but even if the author writes alone, the story is always influenced by many people. One of the most prominent people involved in production of fanfiction is a beta-reader. The term itself derives from the word "beta-tester", which is used to describe people who use beta-versions (that is, working, but not completed versions) of computer software to check it for quality, efficiency and stability before it is released. The relationship between the author and their beta-reader is that of cooperation. The beta-reader's task is to point out potential mistakes and problems, and to suggest solutions. The author attempts to take those into consideration, then the story is discussed again. The whole process bears resemblance to negotiations, and ideally, it should lead to creating a text both the author and the beta-reader deem good. The scope of beta-reader's suggestions varies from author to author. In some relationships, beta-readers suggest major plot changes or removing whole scenes; in others, they just make cosmetic changes.

In her article about the role of beta-reader, Angelina Karpovich notices that a beta-reader combines the functions of a reader, a critic, and an editor. They definitely can influence the text, even if not directly - after all, the final decision lies with the author. Despite that, it is common practice in fandom to name beta-readers when publishing a story, which means that they are considered at least partially responsible for the text.

Of course the audience can also have some degree of influence on "professional" literature. E-mails, blogs, meetings with fans and various conventions allow fans to express their opinions and wishes. However, their influence is somehow limited because of the distance that exists between the author and the audience. In fandom, the situation is quite different. By definition participants are not divided into writers and readers, because many of them are both at once. Additionally, the internet allows for immediate and direct communication between fans through 
I Write. You Write. They Write...

comments posted under stories. The main difference between this and traditional literary criticism is that "professional" criticism is usually created after the work is published, when fans can follow a story while it is being created.

As it was already mentioned, the fans' interpretation very often goes beyond the scope of the original text; it diminishes some of the distance between the text and its reader, and is based on personal experience. Fans often use the same approach when analyzing texts written by other members of fandom. People who comment on and talk about their impressions. They often compare the fic writer's interpretation with their own, accepting it as believable or rejecting it. Since the fans know each other, one can often notice allusion to common experiences, texts read etc. It can be assumed that this is a form of discussion of an interpretation of canon presented by the fic writer. At the same time, however, fanfiction is not only an interpretation, but also a piece of literature in its own right. Commenting on a fic, fans also pay attention as to how it was written. Language, plot, character-building, tension - all of this is noticed and described, like in Zoe's comment on a crime story under construction:

I love crime stories and Mrs Christie, and Hercule Poirot has my undying love. This is why I really, really love the idea of Tuesday Meeting Club. A few ladies watching a movie, then guessing the ending. I immediately imagined a big university building, the professors and their wives, the suburban atmosphere (...)

But... Unfortunately, there is a "but". Too much. There is too much of all this! At the very beginning, you introduced a few new characters, and it's hard to keep track of them. I can't remember their names or their husbands' jobs. All those details really slowed the pace - if they aren't necessary for the plot, maybe it would be better to get rid of some of them? (Zoe 2011, access: 21.05.2012).

This clearly shows that fans not only pay attention to their own feelings or impressions, but also on technical solution that could improve the text. If readers point out inaccuracies or errors, they expect them to be fixed in the following chapters. In some stories, one can see big discrepancies in style between chapters because of changes suggested by readers. Of course not all comments include technical suggestions, or even constructive criticism. A majority is just an expression of positive feelings towards the story. The purpose of this kind of comment is to maintain a relationship between reader and writer. It makes authors feel that their work is appreciated by other fans, but it does not influence the writing process because it lacks 
constructive feedback. Because of this, on some forums the moderators attempt to force the users to include constructive criticism in their comments.

Fans who comment on a story usually expect the author to react; either by saying a few words in the introduction to the next chapter, or by creating a separate post. There is a constant discussion about the text, during which both sides exchange opinions about how it should be shaped.

I don't buy your James, either, and most of all, I don't buy your Remus. I'm sorry, but they seem like spoiled brats here, I'm thinking mostly about James, but Remus is also very "un-Remus-like".

As for James and Remus, well, let's start with Potter. I must admit that I never liked him very much, and the way he was depicted in fanfiction always seemed too idealized to me. I think that's why I went in the opposite direction, making him into... well, a spoiled brat who has some serious issues. (Cattysxx 2006, access: 21.05.2012]

Comments by both readers and writers also have an additional function. Fanfiction obviously is not an independent text; it needs canon in order to exist. Therefore when reading a fic, the fan needs to remember the original. Sometimes, however, there are questions that neither canon, nor fanfiction answers. Holes in the canon are filled by fanfiction, but holes in fanfiction are dealt with differently. Some of them are also developed into separate stories; either by the author, who writes multiple stories in the universum they created, or by other writers, who "tag along". However, it often happens that fans ask questions about details of world buildings or the characters' behavior. Author's replies allow them to create a coherent image of the fictional reality. It also means that comments are even more important in fanfiction research, because they often include important information.

One of the more interesting ways of letting the readers join the creative process is creating polls in which they can decide what will happen next. An example of such an experiment can be The Powers That Be written by CrowNoYami (CrowNoYami 2010, access: 20.05.2013). It is a Harry Potter / Buffy the Vampire Slayer crossover focused on Spike. In this story, Spike returns to the magical world (his real name here is William Malfoy), and searches for his destined partner. However, when Spike arrives to England, he does not know who this person is. As it turns out, neither does the author. At first in the author's notes, she informed that the story would be a slash fic (a story featuring a homosexual rela- 
tionship), but the pairing was not yet established. In author's notes to chapter five, CrowNoYami included information about a poll that was supposed to decide who would be Spike's partner. Harry, Snape, Remus and Draco were featured among the possible choices. The fans were also free to suggest other characters, although the author made some restrictions (it had to be a man, and not Dumbledore). Eventually Harry won, but the author promised to write short scenes with other popular choices as a consolation prize.

\begin{abstract}
It is hard to judge this kind of behavior. On one hand, it can be interpreted as the author's inability to solve the plot, and shifting the responsibility on the readers instead. However, another interpretation of her motives is also possible. She clearly had a well-established story idea. The poll only appeared in chapter five, and it was open for quite a long time. In the meantime, further chapters were written, in which the partner's identity did not play any part. The story is entirely focused on Spike, and the author seems indifferent towards the choice of partner. She let the fans decide what they wanted to read, while she herself fulfilled her goal: to write a story about Spike in the magical world.
\end{abstract}

Polls are common practice in fandom. One of the main reasons why fanfiction is written is because the fans want more than the canon can offer them. They might want to read about what happened next, or take a look at the elements of the canon that were not fully utilized. Sheenagh Pugh describes those expectations as an opposition between wanting "more of" and "more from the text" (Pugh 2005: 19). Many stories are written simply because the fans would like to read them. It leads to all kinds of different fests during which fans ask for stories that meet specific criteria. An especially nice variation of this custom is gifting each other stories for birthdays or Christmas:

This story was written as a gift for Mithiana, after I overdosed her stories and that one song she likes. I'm sorry in advance if anyone feels disappointed.

Thank you, Micia. Happy birthday. Semele (Semele 2005, access: 15.05.2012)

Fanfiction can also be treated as fun and a chance to test one's abilities. An example of such an approach can be games developed in fandom, mostly realized as challenges that can be entered by authors. On fanfiction.net, there is an established practice of authors creating "challenges". The author establishes criteria (for example genre, characters, specific plot elements) that have to appear in stories, and invites people willing 
to participate to write. The most famous challenge like this was one created by Severitus (Severitus 2012, access: 23.05.2013). He called for stories in which it turns out that Snape is Harry's biological father. Apart from this, a few other elements had to be included (Lupin had to be present, Harry's appearance had to be altered etc). The challenge became so popular that all stories in which Snape is Harry's father are commonly called "severitus", even if they do not meet the other criteria of the original challenge.

A more formalized form of writing challenge are duels on Mirriel. The person creating a challenge establishes the condition. After someone accepts the challenge, both authors write stories, who are afterwards asessed by other users in the following categories: idea, style, meeting the criteria of the challenge, canon-compliance, and general impression.

\section{Conclusion}

The main element integrating a fan community is the original text, because it is what cements the fans as a group, and gives them material to create their own art. Fanfiction, thanks to its relationship to the canon, is also a part of creating this cultural community. At the same time, however, it is more that just that. Fans not only write stories based on a shared canon; they also create them together, using elements both from the canon and from other fanmade stories. Being a part of fandom is approaching the text in a specific way as well as interacting with other fans. When looking at fanfiction, one needs to pay attention to the fact that in creating a text (from interpreting the source text to presenting the final product) there is a whole group of people involved, and writing a fic is not over when it is posted. A fic is constantly rewritten by other fans, who comment on it or use it in their own writing. In this context, it seems appropriate to describe fanfiction, following Busse and Hellekson, as an eternal "work in progress". Every separate story, as well as the whole body of fanfiction, constantly grows, transforms, and redefines. At the same time, writing fanfiction is a chance for the fans to discuss both personal matters and scientific problems. It lets the fans learn from one another, have fun together, and communicate on a level different from a casual conversation. In the 1960s, fandom created a statement: Fandom is a way of life". It seems, however, that for the fans creating fanfiction it is writing that became a way of life. 
I Write. You Write. They Write...

\section{Bibliography}

Busse Kristina, Hellekson Karen 2006, Introduction. Work in Progress, [in:] Fan Fiction and Fan Communities in the Age of Internet, Jefferson: McFarland \& Company Inc. [Kindle Edition]

Coleman Susanna 2010, Making Our Voices Heard: Young Adult Females Writing Participatory Fan Fiction, [in:] Writing and the Digital Generation. Essays on New Media Rhetoric, ed. H. Urbański, Jefferson: McFarland \& Company Inc.

Coppa Francesca 2006, A Brief History of Media Fandom, [in:] Fan Fiction and Fan Communities in the Age of Internet, eds. K. Hellekson, K. Busse, Jefferson: McFarland \& Company Inc. [Kindle Edition]

Derecho Abigail 2006, Archontic Literature: A Definition, a History and Several Theories of Fan Fiction, [in:] Fan Fiction and Fan Communities in the Age of Internet, eds. K. Hellekson, K. Busse, Jefferson: McFarland \& Company Inc. [Kindle Edition]

Gąsowska Lidia 2009, Fan fiction, czyli złoto dla zuchwałych. Pomiędzy pragnieniem narracji a realizacją opowieści, [in:] Kody kultury. Interakcja, transformacja synergia, eds. H. Kubicka, O. Taranek, Wrocław: Sutoris.

Hellekson Karen 2010, History, the Trace, and Fandom Wank, [in:] Writing and the Digital Generation. Essays on New Media Rhetoric, ed. H. Urbański, Jefferson: McFarland \& Company Inc.

Jenkins Henry 2007, Everybody Loves Harry, http://henryjenkins.org/2007/05/everybody_ loves_harry.html

Jenkins Henry 2007, Kultura konwergencji. Zderzenie starych i nowych mediów, Wydawnictwa akademickie i profesjonalne, Warszawa.

Jenkins Henry 2006, Fan Fiction as Critical Commentary, http://henryjenkins.org/2006/09/ fan_fiction_as_critical_commen.html

Jenkins Henry 2006, Can One Be a Fan of Hight Art? http://henryjenkins.org/2006/07/can_ one_be_a_fan_of_high_art.html

Jenkins Henry 1992, Textual Poachers. Television Fans \& Participatory Culture, New York: Routledge.

Kaplan Deborah 2006, Construction of Fan Fiction Character Through Narrative, [in:] Fan Fiction and Fan Communities in the Age of Internet, eds. K. Hellekson, K. Busse, Jefferson: McFarland \& Company Inc. [Kindle Edition]

Karpovich Angelina 2006, The Audience as Editor: The Role of Beta Reader in Online fan Fiction Communities, [in:] Fan Fiction and Fan Communities in the Age of Internet. eds. K. Hellekson, K. Busse, Jefferson: McFarland \& Company Inc. [Kindle Edition]

Pugh Sheenagh 2005, The Democratic Genre. Fan fiction in a Literary Context, Glasgow: Bell and Bain Ltd.

R. D. M. 1996, First Fandom, http://www.jstor.org/stable/4240563

Southard Bruce 1982, The Language of Science-Fiction Fan Magazines, http://www.jstor.org/ stable/455177

Wooley Christine 2001-2002, Visible Fandom: Reading The X-Files Through X-Phile, http:// www.jstor.org/stable/20688369 


\section{Agnieszka Oberc}

\section{Fanfiction}

Cattysxx 2006, Re: Lód w sercu, http://forum.mirriel.net/viewtopic.php?f=2\&t=17450 [access: 21.05.2012].

CrowNoYami 2010, The Powers That Be, http://www.fanfiction.net/s/6229179/1/The_Powers_That_Be [access: 31.05.2012].

Semele 2005, Nibylandia, http://forum.mirriel.net/viewtopic.php?t=1839 [access 15.05.2012]

Severitus 2012, Severitus Challange, http://severitus.livejournal.com/5823.html [access: 10.05.2012].

Zoe 2011, Re: Romantyczna kryjówka, http://forum.mirriel.net/viewtopic.php?f=2\&t=15021 [access: 21.05.2012]. 